\title{
A Crítica da razão prática e o estoicismo*
}

\author{
Valério R ohden \\ Universidade Luterana do Brasil
}

resumo No presente trabalho será demonstrada a estreita, embora discreta, relação da filosofia moral de Kant com a ética antiga, especialmente com o estoicismo de Cícero. 0 tema será explicitado mediante uma aproximação entre as obras da Crítica da razão prática e Sobre os fins (De finibus), respectivamente de cada um desses autores. Será destacada a crítica de Kant à identificação entre virtude e felicidade e sua reformulação sintética no conceito de "sumo bem". Na conclusão se torna claro que a realização moral da razão, reivindicada por Cícero, encontra na reformulação de Kant sua determinação mais precisa. palavras-chave estoicismo - idéia - razão - sumo bem - virtude - felicidade

\section{Atmosfera estóica}

A título de introdução ao tema proposto - a presença da ética estóica na C rítica da raz ão prática - , quero em um primeiro momento mostrar como a ética estóica constituiu a atmosfera propícia ao desenvolvimento da filosofia moral de K ant. A seguir abordarei a concepção estóica do "sumo bem", adstrito a uma identificação da felicidade com a virtude; por fim, considerarei a concepção sintética do sumo bem em Kant, a partir da qual ele criticou a concepção analítica estóica. $\mathrm{N}$ a abordagem será privilegiada, em relação ao assunto, a discreta relação entre K ant e Cícero.

Servir-me-ei, nesta introdução, do termo "atmosfera" em seu sentido figurado de "ambiente espiritual e social" (dicionário Houaiss) que envolve um objeto. Formada a partir de "atmos", com o sentido grego de R ecebido em janeiro de 2005. A ceito em maio de 2005. doispontos, Curitiba, São C arlos, vol. 2, n. 2, p.157-173, outubro, 2005 


\section{8}

vapor, "atmosfera" significa no nível físico a camada de gases que circunda um planeta e aí se mantém graças à respectiva força de atração. Em torno daTerra, a atmosfera é a camada de ar que nos permite respirar e viver ${ }^{1}$. Logo, assim como a vida física tem sua atmosfera, também a vida espiritual tem seu ambiente. $E$ se, de um lado, o estoicismo nutriu-se de seu ambiente greco-romano, de outro, a segunda C rítica de K ant encontrou nele a atmosfera propícia à sua reformulação moderna². Portanto, em relação a K ant investigar-se-á aqui sob que condições essa ética originária da filosofia contribuiu vitalmente para a formação do ambiente kantiano, do qual somos herdeiros e a partir do qual hoje pensamos 3 .Vou procurar expressar essa vigência filosófica do estoicismo a partir da tese de $\mathrm{K}$ laus R eich sobre a recepção kantiana das idéias de Platão por meio de $\mathrm{R}$ ousseau e Cícero4.

$\mathrm{R}$ ememoro a propósito o texto de K laus $\mathrm{R}$ eich, $\mathrm{D}$ ieTugend in der I dee: $Z$ ur $\mathrm{G}$ enese von $\mathrm{K}$ ants Ideenlehre - que também abordei no projeto de pesquisa submetido ao Conselho $\mathrm{N}$ acional de $\mathrm{D}$ esenvolvimento $\mathrm{C}$ ientífico e Tecnológico (CN Pq). R eich observa aí que o uso por $K$ ant do termo "idéia" não procede diretamente de Platão mas por meio de Cícero, segundo o qual a idéia não pode existir na realidade mas serve de padrão de medida para orientar o juízo em um determinado domínio e que ele aplica, por exemplo, ao orador e ao vir bonus do livro III do D e officiis. K ant, por sua vez, aplica essa versão ciceroniana de Platão no § 9o da D issertação de 1770 à perfectio moralis = Tugend (virtude), transformando-a em um conceito a priori em sentido estrito5. A propósito da relação R ousseau-K ant sobre o termo "idéia" na versão dada por Cícero, K ant, nas Vorlesungen zur R eligionsphilosophie, edição Pölitz de 1817, p. 109, escreveu: "A gente representa idélas no homem, também em D eus. Elas não são cópias das coisas mas arquétipos das mesmas, pelos quais unicamente são possíveis. R ousseau diz: à construção de uma casa pertencem três coisas: 1. a idéia na cabeça [...], 2. a imago [...], 3. a apparence [...]. Agora, ele [R ousseau] faz uma bela aplicação: o moralista representa a virtude na idéia, o historiador representa-a do modo como os homens efetivamente a possuíram. 0 poeta ou o escritor de teatro representa apenas como ela aparece, meramente a apparence" (apud R EICH , 1964 p. 211).

0 empenho maior de $\mathrm{R}$ eich residiu em descobrir onde $\mathrm{R}$ ousseau expunha essa versão ciceroniana de Platão, que encontrou referida em 
K ant. Localizou- a no texto $D$ el'imitation théatrale $E$ ssai tiré des dialogues de Platon (1764). Aí R ousseau refere-se ao Livro X da R epública, em que a arte aparece como uma espécie de gosto de terceira classe, depois da idéia e da realidade comum. $R$ ousseau combina aí, por assim dizer em sentido ciceroniano, a idéia e o conceito de razão pura, aplicados à virtude. 0 que é que então encontramos em $K$ ant? $R$ esponde $R$ eich: "Platão visto pelas lentes de Cícero com os olhos de R ousseau" (R EICH, 1964, p. 212). Kant com certeza conheceu esse texto de Rousseau e o citou na Vorlesung por volta de 1784. Além disso, na R eflexão 6611 lemos: “I déia é o conhecimento a priori do entendimento, pelo qual o objeto torna-se possível. Ela refere-se ao objeto prático como um principium. Contém em certo sentido a máxima perfeição [...]. Só existe no entendimento [...]. Toda a moralidade repousa sobre idéias e sua imagem no homem é sempre só uma idéia [...]" (KAN T, 1902 ss, vol. XIX, p. 108)6. Segundo a $C$ rítica da razão pura, Platão encontrou suas idéias principalmente no domínio prático, isto é, no que se assenta sobre a liberdade, sob conhecimentos da razão pura. 0 conceito de virtude, entendido como arquétipo, se fosse tirado da experiência, perderia seu sentido. As idéias tornam pela primeira vez possível a experiência do bem. Em outra passagem, na $\mathrm{N}$ achricht von der E inrichtung seiner Vorlesungen..., de 1765, Kant observa que esse método de comparação do que acontece com o que deve acontecer é uma bela descoberta de nossa época. 0 descobridor, segundo $R$ eich, foi R ousseau. Kant escreve nas B emerkungen über das $G$ efühl des Schönen und $E$ rhabenen: " $O$ livro de R ousseau (É mile) serve para corrigir osAntigos" (KAN T, 1902ss., vol. XX, p. 9, apud: R EICH , 1964, p. 214). Serviu também para tornar Kant crítico.

Essa referência ao conceito platônico de idéia, recebido por $\mathrm{K}$ ant pela mediação mais remota de Cícero, teve por objetivo introduzir ao relacionamento entre esses dois autores e, obliquamente, ao estoicismo. Em verdade, não há no âmbito da C rítica da razão prática nenhuma menção específica a Cícero, o estóico romano apreciado por K ant.Tampouco isso se verifica na F undamentação da metafísica dos costumes, em relação à qual a obra de Carlos Gilbert prova em detalhe a influência de Cícero (cf. GILBER T,1994 e também M AR D O M IN G0,1996, pp.1-101). Além disso, depois de ter encontrado em um outro trabalho de Klaus $R$ eich, $K$ ant und die E thik der $G$ rieschen (1935), uma alusão a uma carta de 
Hamann, segundo a qual Kant escrevia em 1784 uma obra de ética contra a interpretação que C hristian Garve fazia de Cícero, investiguei 0 assunto mais de perto na $\mathrm{C}$ orrespondência de $\mathrm{H}$ amann (1965). $\mathrm{N}$ a p. 123 do vol.V da mesma se lê: "K ant deve trabalhar em uma anticrítica - cujo título mesmo ainda não se sabe - ao Cícero de Garve". Q ue a notícia é fidedigna pode ver-se pelo acréscimo na frase seguinte: “Eu visitei-o há oito dias". A notícia impressionou tanto $\mathrm{H}$ amann que ele a repetiu em várias outras cartas, sem grandes diferenças.

Essa era a atmosfera estóica - antes, estóico-romana - da C rítica da razão prática. A nós ela interessa na medida em que pretendemos examinar a relação de Kant com o estoicismo justamente na perspectiva de Cícero. C omo escola pertencente à tradição helenista da fase pós- clássica (séculos III a I a.C), o estoicismo deu, com os epicuristas e os céticos, unidade filosófica e cultural a uma época. Segundo M alte H ossenfelder, as escolas antigas de modo geral estão estreitamente aparentadas entre si: possuem convicções básicas e programas comuns, com variações apenas nas suas conseqüências ou na sua efetivação. 0 fato de elas polemizarem entre si fala em favor de seu estreito parentesco7: possuem uma mesma terminologia, conferem um primado à razão prática sobre a teórica e têm um idêntico princípio fundamental prático. A razão prática, em um segundo tipo de relação com a teórica, faz esta depender também de um conteúdo prático. Por exemplo, para a realização do sumo bem admitimos a imortalidade da alma, mesmo que a razão teórica não a alcance (a razão prática tem o primado em questões sobre as quais não é possível uma decisão teórica). As afirmações do primado da razão teórica sobre a prática decorrem, em parte, da presunção de que o dever-ser deriva do ser (naturalismo ético) e, em parte, da escolha dos meios adequados a seu conhecimento. No estóico C risipo, como também em Epicuro, a Física está a serviço de fins éticos. $\mathrm{N}$ o helenismo a ciência teórica tem de justificar-se a partir de interesses práticos. $\mathrm{M}$ as $\mathrm{H}$ ossenfelder defende a tese de que 0 interesse prático determina decisivamente o conteúdo e mesmo a forma dos sistemas teóricos, como no caso de Sexto Empírico, conformemente ao qual os sistemas foram construídos para justificar nossas fraquezas.

0 princípio prático comum ao helenismo e a toda a filosofia antiga é a eudaimonia (felicidade). $\mathrm{N}$ a polêmica entre estóicos e epicuristas sobre 
virtude e vício, trata-se menos de uma polêmica sobre o telos, o fim mais alto, do que de uma polêmica sobre o caminho para a real ização da eudaimonia. $\mathrm{N}$ em o prazer em Epicuro, nem a virtude nos estóicos é um fim próprio, apenas a eudaimonia possui valor absoluto. Esta, no entanto, permanecerá um conceito vazio se não for melhor determinada, como no caso no conceito de uma "vida bem sucedida". A G lüdkselligkeit (nome alemão para eudaimonia) é limitada a um estado predominantemente interno e espiritual, enquanto eudaimonia refere-se em primeiro lugar a um sucesso exterior (cf. H O SSEN FELDER , 1985, p. 23). Para o helenismo, a boa sorte (o G lück alemão) especifica-se necessariamente de um ponto de vista negativo como "liberdade da excitação interior". Epicuro e os céticos identificam-na como ataraxia (tranqüilidade), em ambos os casos como ausência de fatores que produzam tensão e agitação da alma. De um ponto de vista positivo, os epicuristas entendem a eudaimonia analogamente a uma plena calma do mar (no ânimo) e os estóicos como o curso de vida favorável (W ohlfluss). Q uando um curso de rio flui bem, quando em analogia com ele não se é impedido por redemoinhos e ondas, fala-se de perfeita calma e equilíbrio de ânimo ou de paz interior, segundo as escolas helenistas. A eudaimonia encontra se ameaçada quando o coração depende do que não está disponível ou quando depende de necessidades que não podem ser satiffeitas; portanto, quando não estão ao alcance das forças de cada um. Logo, só se deve desejar o que se consegue satisfazer, sendo-se indiferente para com o restante. 0 princípio fundamental prático torna-se então de "só se reconhecerem aquelas necessidades cuja satisfação se encontra totalmente ao alcance das próprias forças" (idem, p. 20).

\section{Identificação de virtude e felicidade}

U ma abordagem da relação da filosofia moral de Kant com a filosofia antiga requer um exame da questão do sumo bem, em torno de cujo núcleo, como observei, orbitavam todas as suas éticas. Para essa comparação sigo, de um lado, o texto kantiano da C rítica da razão prática e, de outro, 0 do $D$ e finibus de C ícero. $N$ a C rítica da razão prática, a questão é tratada a partir deA 198, “ $D$ a dialética da razão pura na determinação do 


\section{2}

conceito de sumo bem", em que Kant se estende também à determinação das afinidades entre estoicismo e epicurismo, como duas formas opostas de identificação entre virtude e prazer. À diferença dessas concepções, que na determinação do sumo bem estabeleciam uma relação analítica entre os conceitos de virtude e felicidade, $K$ ant aí estabelece uma relação sintética entre eles. A mbas essas éticas, maximamente em sua fase grega, centravam suas reflexões sobre a figura do sábio, que encarnava solitariamente a prática do bem, enquanto a quase totalidade dos demais homens era vista como tola e vivia no mal; não obstante, $K$ ant considerava a característica mais relevante do estoicismo seu conceito de virtude (KAN T, 2003, p. 41; K pV A 22). 0 s estóicos tinham em comum com os acadêmicos e peripapéticos a identificação entre viver segundo a natureza e viver segundo a virtude ${ }^{8}$, que entendiam como forma de vida honesta. Para os epicuristas, a necessidade da sabedoria como arte de viver voltada para o prazer justificava-se diante da insaciabilidade de nossos apetites. 0 u seja, ela era desejável como uma forma superior de prazer, em que também a virtude se fundamentava. Pois, embora todos os prazeres se originem no corpo, os prazeres da alma são maiores que os do corpo: o corpo só nos permite sentir o presente, enquanto a alma pode sentir o passado e o futuro. $R$ ecordações e esperanças aumentam 0 prazer. 0 sábio não depende do futuro, mas 0 espera. O s tolos sofrem com a recordação de suas dores, enquanto os sábios se al egram com a grata recordação dos bens passados. Por isso o epicurista do texto de Cícero também declara que "os homens não poderiam viver prazerosamente sem viver sábia, honesta e justamente" (CICER O, 1988, I 57). Logo, "nenhum tolo é feliz e nenhum sábio é infeliz". Saber buscar alegremente o prazer é ser sábio, virtuoso e feliz. O u seja, a sabedoria epicurista consiste em um pragmatismo da administração racional da vida em vista do prazer.

0 estóico, por sua vez, procura identificar o sumo bem com a virtude, tentando distingui-lo do prazer. Sua justificativa para a eliminação do prazer é a impossibilidade de limitação dos apetites. Por isso ele contesta também o ponto de vista epicurista, da competência dos sentidos para julgar o prazer como bom e a dor como má. Pois só à razão compete julgar sobre coisas divinas e humanas concernentes à sabedoria e à virtude. $\mathrm{N}$ isso o estoicismo concorda com $\mathrm{K}$ ant, mas se afasta dele ao 
afirmar não só que ao prazer é negado ser sede do sumo bem, mas que a ele é negada também sua conexão com a virtude (CICER O, 1988, II, 37). 0 estóico afirma duas teses (ou faz duas formulações da mesma tese): primeiro, de que a razão só reconhece como boa a virtude, não tendo 0 resto nenhum peso ou somente um peso relativo; segundo, de que a virtude é um viver segundo a natureza.

D iferentemente dos epicuristas, para os estóicos cada animal tem sua finalidade, que para o homem não reside simplesmente no comer e no prazer de reproduzir-se, mas no conhecer e agir. Veremos melhor essa diferenciação estóica do homem em relação ao animal pela razão e a virtude, mediante a apreciação de uma passagem memorável do De finibus. Segundo esse parágrafo, que desmembro em cinco pontos,

1) a virtude possui a natureza de ser louvável por si mesma, independentemente de toda a utilidade, prêmio ou vantagem;

2) o que é a virtude depende menos de uma definição do que do juízo concordante de todos os homens a seu respeito, bem como dos exemplos dos melhores, que procedem de um determinado modo simplesmente porque é dever, porque é reto e virtuoso, mesmo vendo que não ganham nada com isso;

3) os homens distinguem- se dos animais em um ponto: eles possuem razão. A razão é capaz de conhecer as causas e conseqüências, estabelecer semelhanças, vincular o passado, o futuro e o presente e, enfim, projetar a estrutura completa de uma vida em si conseqüente. A razão faz que cada homem procure a convivência com os outros e concorde com eles pela natureza, linguagem e ações (cf. CIC ER O , 1988, II , 45)9; 4) esse desenvolvimento da razão se dá por um crescimento do amor, primeiro à família e aos seus, a seguir à formação de uma comunidade política e daí a todos os homens. Cícero justifica- o com uma frase de Platão, de que o homem não veio ao mundo para si só, mas também para sua pátria e os seus, com uma parte menor para si próprio (CICER O, 1988, II, 47) e

5) o homem recebeu os apetites para amar 0 verdadeiro, 0 justo e 0 bom e detestar o falso, 0 enganador e a maldade.

A ssim, segundo a interpretação que Cícero faz do estoicismo, não há nenhum bem além da virtude. $A$ virtude é a consumação da razão. 0 que 


\section{4}

concorda com a razão é dever: 0 dever é uma forma de agir que encontra aprovação e pode ser justificada. A razão é a forma de vida do homem, para a qual tudo toma sentido: "Assim como nossos membros corporais foram-nos dados com vistas a uma determinada forma de vida, assim

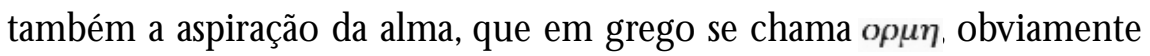
nos foi dada não com vistas a algum modo qualquer de vida, mas para uma forma de vida bem determinada. 0 mesmo vale para a razão e para a razão perfeita" (CICER O, 1988, III, 23).

$\mathrm{N}$ ão era de admirar, pois, que $\mathrm{K}$ ant encontrasse em um livro como 0 D e finibus, de Cícero, uma inspiração ininterrupta para sua reflexão moral. Por isso, para avançarmos e diferenciarmos a concepção kantiana do sumo bem da sua concepção ética estóica, leiamos antes o grande louvor feito a ela na R eligião nos limites da simples raz ão:

"Esses filósofos tomaram o seu princípio moral universal da dignidade da natureza humana, da liberdade (como independência do poder das inclinações); um princípio melhor e mais nobre tampouco teriam podido pôr como fundamento. Eles desse modo hauriram a lei moral imediatamente da razão, unicamente legisladora e ordenante por meio dela; e assim objetivamente, no que concerne à regra, e também subjetivamente, no que concerne ao motivo, se atribuímos ao homem uma vontade não corrompida, de sem mais assumir essa lei em suas máximas, estava tudo indicado de modo totalmente correto" (KAN T, 1977, vol. 8, p. 709-710; A 62-63, B 68-69).

Então, em que consistia a diferença entre kantismo e estoicismo?

\section{Uma concepção sintética do sumo bem}

Veremos aqui mais especificamente em que se resume a mudança de concepção de Kant em relação ao antigo conceito de sumo bem. A primeira característica dessa virada é que, enquanto esse conceito ocupava posição central na ética antiga, isso já não acontece na orientação formal de K ant.Trata-se, não obstante, de um conceito mais relevante do que em geral se supõe, na medida em que a apetição essencial de uma razão prática consiste em querer realizar-se e o sumo bem é a matéria 
dessa realização - mas em $K$ ant jamais seu pressuposto. Já antes de sua abordagem temática, $K$ ant escrevia sobre a implicação entre forma e matéria da lei: "Portanto a simples forma de uma lei que limita a matéria tem que ser ao mesmo tempo uma razão para acrescentar essa matéria à vontade, mas não para pressupô-la". M atéria e forma, no entanto, se complementam, quase se integram, se, ao tomar a felicidade por objeto, pressuponho a universalidade como sua lei. 0 u seja, não há incompatibilidade entre felicidade e moralidade, desde que eu não eleve a minha felicidade pessoal a um princípio. "Seja a matéria, por exemplo, minha felicidade própria. Se atribuo esta a cada um (como no caso de entes finitos, de fato, nos é permitido fazer), ela somente pode tornar-se uma lei prática objetiva se incluo na mesma a felicidade dos outros. Logo, a lei de promover a felicidade dos outros não surge da pressuposição de que aquela seja um objeto para 0 arbítrio de cada um, mas simplesmente do fato de que a forma da universalidade, que a razão necessita como condição para dar a uma máxima do amor de si a validade objetiva de uma lei, torna se o fundamento determinante da vontade; portanto, não era o objeto (a felicidade dos outros) o fundamento determinante e, sim, a simples forma legal, pela qual eu limitava a minha máxima fundada sobre a inclinação para propiciar-Ihe a universalidade de uma lei" (KAN T, 2003, p. 117; KpV A 61).

K ant acrescenta que o conceito de obrigação surge da limitação da máxima à forma da universalidade e não do acréscimo do motivo, a felicidade dos outros. Logo, ele não universaliza a matéria e por isso mantém o conceito de felicidade natural ou própria, que cada um busca espontaneamente. Todavia, como ente finito, o homem não é espontaneamente bom, mas sua bondade é conquistada contrariando as inclinações, isto é, submetendo-as à condição da sua compatibilidade recíproca mediante uma lei da razão, cuja necessidade prática é fruto de nossa liberdade moral.

Com isso deverá ficar mais fácil a compreensão da preeminência da virtude, na sua composição com a felicidade com os dois elementos do sumo bem. Para K ant, há que distinguir entre "sumo bem" (höchster $G$ ut) e "bem supremo" (oberster $G$ ut). 0 sumo bem é composto de um bem supremo, a virtude, e de um segundo elemento, a felicidade. $M$ as a virtude, embora seja a condição suprema de tudo o que é desejável, não 


\section{6}

é aí o bem completo e consumado, contrariamente ao que vemos nos estóicos (é verdade que C ícero, no entanto, como registrei, lucidamente admitiu na direção de $K$ ant que a virtude da alma não podia ser todo 0 bem, que incluía também o cuidado do corpo). 0 bem completo e consumado em $K$ ant requer o concurso da felicidade como objeto da faculdade de apetição de entes finitos. Em resumo, a virtude é o bem supremo, mas não o sumo bem, que inclui além dela a felicidade.

Esse reconhecimento kantiano da felicidade como um componente da realização da prática moral é importante: a pessoa que pratica a virtude torna-se digna da felicidade, merecendo-a. É verdade que esse direito, por assim dizer, nasce da sua condição de ser natural. 0 u seja, ela é buscada naturalmente, por meio da cultura, como um "fim último" (letz ter $Z$ weck) da vida de cada um ${ }^{10}$. M as aqui se fala que, se o homem não a conquista naturalmente, ou mesmo que a conquiste desse modo, de qualquer maneira deve compatibilizá-la com a virtude. Se da C rítica da faculdade do juízo aprendemos que o homem como ser moral torna-se fim para si mesmo, liberdade, e que a partir dessa perspectiva vê finalisticamente a natureza, vê também a própria felicidade, enquanto busca natural, em um novo contexto, o moral. Esse novo contexto não implica a supressão da sua condição de felicidade natural, apenas requer a sua compatibilidade com a felicidade dos demais. Analogamente ao que disse Kant de R ousseau no plano sócio-jurídico11, poderíamos dizer que a inclusão da felicidade em um espaço moral, que é o da convivência universal enquanto ser humano, não diminui a felicidade de cada um - antes a aumenta (porque então não apenas eu cuidarei da minha felicidade e, além disso, à custa dos demais, mas todos estarão cuidando dela o tanto quanto da sua própria). A autoconsciência moral torna-se base desse conceito heurístico de finalidade (cf. KAN T, 1993, § 84, p. 275; KU, B 396; cf. também R O H DEN , 1995).

$\mathrm{Na} C$ rítica da razão prática Kant justifica, do ponto de vista de um querer não contraditório, a inclusão da felicidade no sumo bem: "Pois ser carente de felicidade e também digno dela, mas apesar disso não ser partícipe dela, não pode coexistir com o querer perfeito de um ente racional [...]" (KAN T, 2003, p. 393; K pV A 199). Kant fala então aí de felicidade como componente do "sumo bem de um mundo possível". Só nesse conjunto, de que a virtude é a condição suprema, ele é um "bem 
consumado". Em contrapartida, a felicidade não é por si só algo absolutamente bom, mas pressupõe como condição a conduta moral.

À diferença dos antigos, $K$ ant afirma que a conexão necessária entre essas duas determinações, como razão e conseqüência, não é só analítica e lógica, mas sintética e real, submetidas aquela à lei de identidade e esta à lei de causalidade (em sentido prático). Q uando penso em virtude e em felicidade, tenho duas máximas diversas, duas consciências diversas como fundamento, que precisam unificar-se, ou seja, que não são analiticamente uma só.

Epicurismo e estoicismo em relação ao sumo bem "procuravam a unidade do princípio segundo a regra de identidade", mas cada um divergindo do outro em relação a qual era o conceito fundamental. A oposição, segundo K ant, dava-se da seguinte maneira: "O epicurista dizia: ser autoconsciente de sua máxima que conduz à felicidade, eis a virtude; e o estóico: ser autoconsciente de sua virtude, eis a felicidade" (KAN T, 2003, p. 395; K pV A 200). Eles esquadrinhavam uma identidade entre conceitos extremamente desiguais. $M$ as procediam opostamente enquanto um buscava essa identidade no plano sensível e o outro buscava a no plano racional, como independência da razão prática de todos os fundamentos determinantes sensíveis. Para um, o conceito de virtude estava contido na máxima de promoção de sua própria felicidade e, para outro, o sentimento de felicidade já estava contido na consciência de sua virtude. Temos aí duas totalidades diversas com a mesma matéria, variando apenas o seu modo de vinculação. Para o estóico a virtude é o sumo bem total, sendo a felicidade apenas a consciência de sua posse no estado do sujeito. Para o epicurista, a felicidade é o sumo bem total e a virtude apenas a forma da máxima para concorrer a ela.

Kant já provara na A nalítica da razão prática a heterogeneidade dessas máximas em relação a seu princípio supremo. Felicidade e moral são dois elementos totalmente diversos, de modo que a sua vinculação não pode ser conhecida analiticamente. Trata-se de uma síntese de conceitos. A lém disso, ela é conhecida a priori, quer dizer, não podemos inferi-la da experiência real, mas temos de pensá-la no nível de uma experiência possível e necessária. A possibilidade do sumo bem não depende de princípios empíricos, logo sua dedução tem de ser transcendental. 0 u seja, K ant tem que demonstrar como essa síntese é possível e necessária a priori. "É a 


\section{8}

priori (moralmente) necessário produzir o sumo bem mediante a liberdade da vontade" (KAN T, 2003, p. 401; KpV A 203).

Kant fará essa demonstração a partir, primeiro, da"A ntinomia da razão prática" (K AN T, 2003, p. 403 ss; K pV A 204 ss.) e, segundo, da “Supressão crítica da antinomia da razão prática" (KAN T, 2003, p. 405 ss; K pV A 205 ss.). N o primeiro caso, ele dirá que a conexão prática das causas e efeitos no mundo envolve um conhecimento das leis naturais e, então que, se a promoção do sumo bem ordenada pela lei moral for impossível, também a lei moral o será. A solução é dada mediante uma demonstração prática da existência de Deus. Primeiro, Kant demonstrara que não existirá colisão entre necessidade natural e liberdade, se os eventos forem pensa dos como fenômenos. 0 homem pensado como noumenon pode ser livre determinante de certos eventos. A proposição estóica, de que a virtude promove necessariamente a felicidade, não é falsa de modo absoluto, mas apenas condicional. K ant, porém, pensa esse nexo entre moralidade e felicidade mediante $D$ eus, porque a vinculação que nós podemos estabelecer com a felicidade como objeto dos sentidos é contingente e, portanto, insuficiente para o sumo bem. Deus torna-se a base de uma possível vinculação natural e necessária entre consciência da moralidade e a justa expectativa de felicidade proporcional a ela. 0 desenvolvimento desse ponto dá-se mais adiante na seção "A existência de Deus como um postulado da razão prática” (cf. KAN T, 2003, p. 441 ss; K pV A 223 ss.), precedido do postulado da imortalidade.

\section{Conclusão}

Para concluir, reapreciemos o aí implicado conceito de felicidade. De acordo com o que nos diz o texto, "felicidade é o estado de um ente racional no mundo para o qual, no todo de sua existência, tudo se passa segundo seu desejo e vontade e depende, pois, da concordância da natureza com todo o seu fim, assim como com os fundamentos determinantes essenciais de sua vontade" (KAN T, 2003, p. 443; KpV A 224). Por isso Kant poderia aqui dizer que a felicidade vista desde a perspectiva do seu todo ou de seu fim é o mesmo. Ambos são uma idéia, portanto, uma unidade de natureza e razão. Kant justifica aí que, não 
sendo 0 agente racional ao mesmo tempo causa do mundo e da natureza (dos quais a felicidade depende), a lei moral se apresenta como fundamento para essa interconexão necessária entre moralidade e felicidade proporcionada a ela. $\mathrm{N}$ ós devemos promover o sumo bem, mas ao mesmo tempo foge de nossas forças a sua consumação. Por isso temos de pensar um ser que possua o fundamento da desejada interconexão, com o que o postulado da possibilidade do sumo bem converte-se em postulado da existência de D eus.

A tese contém um paradoxo: de que a promoção do sumo bem seja um dever e que ao mesmo tempo não dependa inteiramente de nós, isto é, não esteja totalmente ao nosso alcance. $K$ ant, no entanto, distingue entre necessidade subjetiva e necessidade objetiva prática (dever). Eu não tenho deveres em relação à existência, que envolve a razão teórica. U m dever em relação ao sumo bem concerne apenas ao empenho por sua promoção no mundo (cf. KAN T, 2003, p. 447; K pV A 226).

As escolas gregas não chegaram à solução da questão do sumo bem, porque dispensavam a existência de Deus e imaginavam alcançar a virtude plenamente nesta vida (cf. KANT, 2003, p. 451; K pV A 228). Com isso se excederam em relação à capacidade do homem como sábio, " para além de todos os limites de sua natureza", admitindo algo contra ditório em relação ao que conhecemos do homem. Por outro lado, o seu sábio foi tornado independente da natureza e igualado a uma divindade. Eles integraram a felicidade total mente à moralidade, contra o que reclamava a sua própria natureza.

M uito mais identificada com a consciência kantiana da finitude humana revelou-se a ética do cristianismo, para o que, igualmente, a virtude era aproximação infinita e a felicidade não era totalmente alcançável nesta vida. Dessa consciência tanto de fraqueza quanto de mérito emergia o conceito-chave da esperança, pelo qual se passa da moral à religião. M as o passo à religião não pertence à filosofia moral, que trata do bem praticável nesta vida entre seres humanos livres. Estes superam sua propensão solipsista pela abertura à razão. A razão, como sendo 0 comum a eles - vimo-lo em Cícero - aspira a realizar-se. Sua realização coincide com o sumo bem humano. 


\section{0}

* Este trabalho, após ter sido apresentado no "I C olóquio de H istória da Filosofia - Bicentenário da morte de Kant" ( $M$ arília, março de 2004), foi reapresentado nas VI Jornadas N acionales Agora Philosophica, - "El legado de Immanuel Kant: actualidad y perspectivas", ocorridas em setembro de 2004 na cidade de M ar del Plata, Argentina. Com nosso consentimento, ele foi também publicado nas Actas dessas Jornadas.

1 A respiração, no entanto, parece não constituir no homem um fenômeno de mera dependência externa, mas provir da conjunção alma-corpo e sobretudo de um princípio interior de vida que se identifica com a alma. 0 termo alemão atmen e o prefixo atmos se comunicam. Segundo H ermann Paul, aquele termo procede do indiano antigo ou sânscrito (uma língua falada no norte da Índia no primeiro milênio a. C.), no qual atma significava respiração e alma. Cf. paralelamente $G$ ênesis 2, 7. Também os termos latinos anima/ animus têm a ver com o grego anemos, vento, sopro. A nima "é o princípio da vida espiritual" (G eorges) ou, segundo Kant, "o ânimo é por si só inteiramente vida (o próprio princípio da vida)" (KAN T, 1993, B 129. trad. p. 124; por um lapso de digitação, na tradução faltou a parte entre parêntesis dessa citação, "o princípio da vida”). Kant explicou o prazer estético como sentimento de vida (cf. KANT, 1993, B 4, trad. p. 48). A seguinte frase de Goethe, que vincula esteticamente vida e atmosfera, talvez sirva de fecho a este assunto: " $U \mathrm{~m}$ dich, $A$ delheid, ist eine $A$ tmosphäre von $L$ eben, M ut./ A ti, A delaide, envolve uma atmosfera de vida, coragem" (de "G oetz von Berlichingen" apud PAU L, 1992, p. 56; 0 destaque é meu). Assim, podemos concluir, o estoicismo foi essa atmosfera inspiradora e vivificadora da filosofia moral de Kant.

$2 \mathrm{~K}$ ant fundou esse seu procedimento interpretativo num princípio hermenêutico que expressou na C rítica da razão pura (K AN T-1983, KrV A 314/ B 370; trad. p. 186) e que formulou justamente em vista de Platão, ou seja, de que o póstero de um autor pode compreendêlo melhor do que ele mesmo se compreendeu.

${ }^{3} \mathrm{~A}$ propósito da nossa proximidade com Kant e dele com a filosofia antiga, reproduzo minhas declarações à P rogramação maio/ junho 2004 do Goethe-Institut Porto A legre: "Suponhamos que a definição que $R$ ichard $R$ orty deu do que significa ser filósofo esteja correta: filósofo é quem se ocupa com Platão e K ant. Então sempre que filosofarmos discutiremos com o autor da R epública. E então também 0 autor das três $C$ ríticas será nosso contemporâneo. 0 u seja, 0 pensamento de Kant estará tão vivo quanto a nossa capacidade de pensar por nós próprios. Pensar, portanto, significará discutir com Kant. Com ele aprendemos a ser críticos nos âmbitos do conhecimento, da ação e da vida. Kant torna-se imprescindível ao nosso tempo e a todo tempo em que houver pensamento. Logo, com os duzentos anos de sua morte, na verdade, comemoramos a vitalidade intrínseca de uma filosofia. A frase com que Kant concluiu a C rítica da razão pura: 'Só o caminho crítico ainda está aberto', revela-se como certa. Se, como ele também afirmou, um filósofo posterior entende um autor melhor do que ele próprio se entendeu, então Kant desenvolveu um pensamento aberto para o futuro. 0 futuro dele somos nós".

4 Segundo declaração oral de M aximilian Forschner, pesquisador kantiano da filosofia estói$\mathrm{ca}, \mathrm{K}$ ant manteve permanentemente sobre sua mesa de trabalho apenas dois livros: $0 \mathrm{D}$ e finibus (Sobre os fins, 47 a. C.) e o D e offiäis (Sobre os deveres, 44 a. C.), de Cícero. Kant lera o último já em seu período colegial (há uma tradução brasileira do mesmo publicada pela $M$ artins Fontes, 2000). Se a isso ligarmos também que ele mantinha sobre a parede de sua casa apenas o retrato de $R$ ousseau e que por causa da leitura de seu E mílio deixou uma única vez de dar a sua caminhada diária, então inferiremos desses dois dados que ambos os autores

doispontos, Curitiba, São C arlos, vol. 2, n. 2, p.157-173, outubro, 2005 
eram- Ihe os mais caros.

5 Segundo essa passagem, um dos fins dos conceitos do entendimento é dogmático, cujos princípios gerais "conduzem a algum modelo concebido apenas pelo entendimento puro como medida comum no que respeita à realidade de todos os outros, o qual é a perfectio noumenon", com um sentido em parte teórico concernente ao ser e D eus, e um sentido prático, concernente à liberdade, no caso, à perfeição moral, que serve como critério de ajuizamento do que não é perfeito, mediante um processo de limitação negativa. Escreve aí Kant: “Em toda espécie de coisas cuja quantidade é variável, o máximo é a medida comum e o princípio do conhecimento. 0 máximo de perfeição chama-se presentemente 'ideal', para Platão a 'idéia' (como a idéia de sua república) - e é o princípio de toda as coisas que estão contidas na noção geral de alguma perfeição, na medida em que se considera que os graus menores apenas podem ser determinados por limitação do máximo" (KAN T, 1985, p. 49).

6 D ada a importância para o leitor dessa longa R eflexão, da época em torno de 1769-1770, transcrevo-a aqui inteira, e que traduzo a partir da edição da Academia, cujas partes entre colchetes são acréscimos desse editor, enquanto as entre os sinais" <...>" pertencem ao tradutor: "(0 conceito, a idéia, o ideal. 0 conceito é um fundamento geral de distinção (o traço característico). U nicamente 0 conceito a priori tem verdadeira universalidade e é o principium das regras. Da virtude só é possível um ajuizamento segundo conceitos, por conseguinte a priori. 0 ajuizamento empírico segundo intuições em imagens ou de acordo com a experiência não fornece nenhuma lei, mas meramente exemplos, que requerem para ajuizamento um conceito a priori. M uitos são incapazes de deduzir seus princípios a partir de conceitos. I déia é o conhecimento [do] a priori [puro] (* do entendimento), pelo qual o objeto torna-se possível. Ela refere-se ao objetivamente prático como um principium. C ontém em certo sentido a máxima perfeição. U ma planta $<G$ ewächs $>$ só é possível segundo uma idéia. Ela só existe no entendimento e no homem em conceitos. 0 sensível é só a imagem, por exemplo, na casa a idéia contém todos os fins. 0 esboço é somente o sensível, ao qual a idéia se conforma. Toda a moralidade baseia-se em idéias, e sua imagem no homem é sempre incompleta. N 0 entendimento divino trata-se de intuições de si mesmo, por conseguinte, de arquétipos. - A representação de um objeto dos sentidos conformemente a uma idéia e à perfeição intelectual nela é ideal. I deais concernem somente a objetos do entendimento e existem só no homem e são nele fictiones. Trata-se de uma invenção $<$ E rdichtung $>$, para pôr uma idéia na intuição in concreto. - O s três ideais da moralidade a partir de conceitos. 0 ideal místico da intuição intelectual de Platão. Santidade é ideal da influência sobrenatural.

(* Conceito de planta, mas não idéia))".

7 “É um velho conhecimento sociológico que grupos se combatem tanto mais fortemente, quanto mais estreitamentes se encontram relacionados" (H O SSEN FELDER, 1985, p. 12).

$8 \mathrm{C}$. a respeito meu trabalho "V iver segundo a idéia de natureza", apresentado no Colóquio $K$ ant da U niversidade Federal de Santa C atarina em 02/ 06/ 2004 (inédito).

${ }^{9}$ A razão possui ainda outras características: revela-se pela sua largueza, grandeza, é mais própria para ordenar que obedecer, é freqüentemente invencível, representa ordem e medida. $\mathrm{N}$ ão é irrefletida nem jamais prejudica al guém. $\mathrm{A}$ beleza e dignidade das formas corporais, das palavras e dos atos é sua afiguração.

10 Todavia, do mesmo modo como numa comunidade humana a condição natural tem de

doispontos, Curitiba, São C arlos, vol. 2, n. 2, p.157-173, outubro, 2005 


\section{2}

adaptar-se às condições de adequação recíproca, visível num estado de direito, assim o fim último natural tampouco é o "fim terminal" (E ndzweck) do homem. Este situa-se ao nível da razão, em que o homem deixa de pertencer a uma escala animal (em que a felicidade é fim último natural individual), sem consideração dos demais. $\mathrm{N}$ o nível da razão, 0 indivíduo torna-se ao mesmo tempo fim para si mesmo e, sob a condição da igualdade - de ver a todos os outros da mesma forma como um fim, torna-se fim dos outros e os toma também como seu próprio fim.

11 “ $N$ ão se pode dizer que o Estado, o homem no Estado, tenha sacrificado uma parte de sua liberdade exterior inata a um fim, mas < que> ele abandonou totalmente a liberdade sem leis selvagem para reencontrar a sua liberdade em geral, não diminuída, em uma dependência legal, isto é, em um estado jurídico; porque esta dependência surge de sua própria vontade legisladora" (KAN T, 1977, vol. 8, p. 434, § 47, A 169/ B 199).

\section{Referências bibliográficas}

CÍCER O, M.T. 1988. D e finibus bonorum et malorum / Ü ber die Z iele des menschlichen $\mathrm{H}$ andelns. Edição e tradução: O lof Gigon.

M ünchen/Zürich: Ártemis.

GILBERT, C. M . 1994. D er E influss von C hristians $G$ arve Ü bersetz ung $C$ iceros " $D$ e offiais" auf $K$ ants " $G$ rundlegung zur M etaphysik der Sitten". $R$ egensburg: $R$.Verlag.

H AM AN N , J. G. 1965. B riefwechsel.V.V: 1783-1785. W iesbaden: Insel.

H O SSEN FELDER , M . 1985. D ie Philosophie der A ntike 3. Stoa, E pikurismus und Skepsis. In: $\mathrm{G}$ eschichte der Philosophie. H rsg. von Wolfgang R öd, Band III. M ünchen: Beck.

KAN T, I 2003. C rítica da razão prática. Edição bilíngüe.Tradução Valerio R ohden. São Paulo: M artins Fontes.

.1983. C rítica da raz ão pura. Tradução Valerio R ohden e U do M oosburguer. C oleção O s Pensadores. São Paulo, A bril C ultural.

1902 ss. R eflexionen zur M oralphilosophie, in: KAN T, I. K ants

W erke, Ed. Königlich Preussischen A kademie der W issenschaften, B erlin, G eorg R eimer, <A kademie Text-A usgabe, Berlin, Walter de Gruyter \& C 0.>, vol. XIX. . 1985. D issertação de 1770. Trad. Leonel R . Santos. Lisboa: 
Imprensa $\mathrm{N}$ acional- $\mathrm{C}$ asa da M oeda.

. 1993. C rítica da faculdade do juízo. Trad.Valerio R ohden e

António $M$ arques. $R$ io de Janeiro: Forense $U$ niversitária. . 1977. W erkausgabe (ed. W ilhelm Weischedel). Frankfurt am

M ain: Suhrkamp, vol 8 (D ie M etaphysik der Sitten).

M AR D O M IN GO, J. 1996. Estudio preliminar. In: KANT, I.

F undamentación de la metafísica de los costumbres. Edición bilingüe; trad.

José $M$ ardomingo. Barcelona: A riel.

PAU L, H . 1992. D eutsches W örterbuch. T übingen: N iemeyer.

R EICH , K. 1964. D ieTugend in der Idee. Zur Genese von Kants I deeenlehre, in: H. D elius \& G. Patzig. A rgumentationen. Festschrift für Joseph Klönig. Göttingen:Vandenhoeck \& R uprecht.

RO HDEN ,V. 1995. "Juízo e reflexão de um ponto de vista prático", in: 0 que nos faz pensar, $R$ io de Janeiro, n. 9, p. 40-53, out.. . 2004. V iver segundo a idéia de natureza. Artigo apresentado no Colóquio Kant, ocorrido em Florianópolis em 02.jun.2004. Digit. 
174

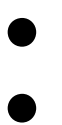

